\title{
Qualidade de Software Percebida pelos Usuários do Sistema SIAFI: Avaliação de um Instituto Federal em Minas Gerais
}

\author{
Cristiana Fernandes De Muylder \\ Universidade FUMEC - Brasil \\ cristiana.muylder@fumec.br \\ Jefferson Lopes La Falce \\ Universidade FUMEC - Brasil \\ jefferson.la.falce@gmail.com \\ Paulo Henrique Pimentel Veloso \\ Instituto Federal de Educação Ciência e Tecnologia do Norte de Minas Gerais - Brasil \\ paulo.veloso1@ifnmg.edu.br
}

\section{Resumo}

Este artigo visa apresentar, através do prisma dos quesitos de qualidade de uso de software listados pela ISO/IEC 9126-1, a percepção dos usuários de um sistema utilizado nas instituições federais de governo, o SIAFI. A pesquisa realizada através de entrevista semiestruturada com servidores dos campi de Januária e Montes Claros destinou-se a registrar suas impressões de maneira a produzir uma interpretação da percepção de servidores públicos sobre o sistema SIAFI. Portanto, objetivou-se avaliar a percepção dos usuários dos níveis operacional e gerencial sobre qualidade de uso de software relativa ao sistema de informação SIAFI. A pesquisa apontou que a maioria dos servidores de nível operacional entrevistados se apresentaram satisfeitos com o software, ao passo que usuários detentores de cargo em comissão expressaram que o sistema ainda é ineficiente quanto a informações que deveriam auxiliar os gerentes. O sistema foi considerado seguro e rápido, apesar de alguns entenderem que existem falhas significativas, principalmente no que tange à entrada de dados e interface (sistema e usuário) que provocam retrabalho. Dentre as considerações da pesquisa, destacam-se maior ênfase em relação ao treinamento prévio dos usuários do SIAFI e reavaliação sobre níveis de acesso ao sistema praticados no Instituto. 
Palavras-chave: qualidade de uso, software, qualidade em serviço, SIAFI, ISO 


\title{
Software's Quality Perception by SIAFI System Users: Evaluation of a Federal Institute in Minas Gerais (Brazil)
}

\author{
Cristiana Fernandes De Muylder \\ Universidade FUMEC - Brasil \\ cristiana.muylder@fumec.br \\ Jefferson Lopes La Falce \\ Universidade FUMEC - Brasil \\ jefferson.la.falce@gmail.com
}

Paulo Henrique Pimentel Veloso

Instituto Federal de Educação Ciência e Tecnologia do Norte de Minas Gerais - Brasil paulo.veloso1@ifnmg.edu.br

\begin{abstract}
This article aims to present, through the prism of the questions of quality of use of software listed by ISO / IEC 9126-1, the perception of users of a system used in Brazil's federal government, SIAFI. The research conducted through semi-structured interview with the campus servers Januaria and Montes Claros was intended to record their impressions in order to produce an interpretation of the perception of public servants on the system SIAFI. Therefore, the objective was to analyse the users' perception of managerial and operational levels on quality of use of software on the system information SIAFI. The survey showed that most servers are operational level respondents were satisfied with the software, while users in committee office holders expressed that the system is still inefficient and the information that should assist managers. The system was considered safe and fast, although some consider that there are significant gaps, especially in regard to data entry and interface (system and user) that cause rework. Among the considerations of the research include a greater emphasis on the prior training of users and re SIAFI on levels of access to the system practiced at the Institute
\end{abstract}

Keywords: quality of use, software, quality in service, SIAFI, ISO 
Com um cenário cada vez mais competitivo nas organizações tanto privadas quanto públicas, torna-se necessário a prestação de serviços com maior eficiência e eficácia. Neste sentido o uso de sistemas de informação pode oferecer uma vantagem para que as organizações tenham presteza na realização dos serviços internos e externos. Embora a utilização de sistemas seja uma ferramenta importante para as organizações, nem todas as organizações possuem sistemas capazes de atenderem o público alvo. No caso da administração pública um dos sistemas projetados para possibilitar maior eficiência é o Sistema Integrado de Administração Financeira do Governo Federal (SIAFI).

O SIAFI, sistema computacional implantado em 1987 nos segmentos de governo com intuito principal de gerir suas informações contábil-financeiras, é objeto central desta pesquisa. O SIAFI, já é utilizado há mais de vinte anos no Instituto Federal de Educação, Ciência e Tecnologia do Norte de Minas Gerais (IFNMG). Os usuários desse sistema são funcionários públicos de segmentos administrativos diversos do instituto, tanto do campus Januária (MG) quanto da reitoria, localizada na cidade de Montes Claros (MG).

As avaliações de qualidade na prestação de serviços têm sido constantes na literatura. Estudos como os de Fadel, e Regis Filho (2009); Raja, e Kumar (2011) e La Falce, De Muylder, Presot, e Toivanen (2012) entre outros avaliam a qualidade no serviço público utilizando o modelo SERVQUAL de Parasuraman, Zeithaml, e Berry (1985). Outros estudos investigaram a qualidade em serviços por meio de entrevistas para identificar dimensões de qualidade percebidas, exemplo dos estudos de Pencarelli, Splendiani, e Cini (2013) e Abdi, Lind, e Birgisson (2014). Estes estudos apontam para a necessidade constante de se avaliar a prestação de serviços e sua qualidade.

Diante do exposto, o estudo apresentado pretende descrever a convergência da percepção de qualidade do uso do sistema de informação SIAFI pelos usuários de nível transacional/operacional e gestores de nível gerencial do Instituto Federal do Norte de Minas Gerais. Dessa forma, o trabalho apresenta o seguinte problema de pesquisa: Qual a percepção dos usuários de nível operacional e gerencial relativa à qualidade de uso do sistema de informação SIAFI? 
A escolha do tema deste trabalho, justifica-se inicialmente pela considerável incorporação do sistema SIAFI como ferramenta do serviço público federal nas últimas décadas, (em especial, na perspectiva organizacional do IFNMG - Campi Januária e Montes Claros), observando as mais diversas aplicabilidades desse sistema na instituição.

$\mathrm{Na}$ dimensão da gestão de pessoas (funcionários usuários do sistema), a pesquisa poderá oferecer subsídio para o entendimento da percepção de qualidade em relação ao SIAFI, de funcionários públicos pertencentes a níveis hierárquicos e com acessos diferentes ao programa e a seus módulos.

Para o meio acadêmico, o estudo poderá somar-se às demais pesquisas existentes nos últimos anos correlacionando serviço público ao tema. Também poderá favorecer o entendimento dos administradores públicos acerca das possíveis interferências da percepção de qualidade ao uso de sistemas de informação já consolidados pela gestão pública governamental.

\section{Desenvolvimento}

Neste capítulo serão abordados os referenciais sobre qualidade de Produtos, a administração pública, sistemas de informação, qualidades em serviço e o sistema SIAFI.

\section{Qualidade de Software}

Estudos relacionados à qualidade foram enfoque nas últimas décadas pela engenharia de software (Pressman, 2011). Caracterizando a avaliação de softwares, ligados à sistemas de informação, Ammenwerth, Iller, e Mahler (2006), afirmam que trata-se de um estudo para medir e investigar os atributos de um sistema ou software, quanto ao desenvolvimento, implementação e a operação em um determinado contexto.

No Brasil, avaliação da qualidade de softwares encontra normas específicas que orientam o processo de avaliação. De acordo com a ABNT (2003), a ISO IEC/14598 (Avaliação do produto de software) e a ISO/IEC 9126-1 (Engenharia de Software - Qualidade do produto), substituíram a NBR 13596. A norma NBR13596, publicada no ano de 1996, 
definia as características de qualidade de software, as quais foram preservadas pela ISO/IEC 9126, que se distingue da anterior principalmente por:

- inclusão das subcaracterísticas em caráter normativo, baseadas, em sua maioria, no anexo informativo da NBR 13596, que contém as subcaracterísticas de qualidade;

- especificação de um modelo de qualidade;

- introdução de qualidade em uso;

- remoção do processo de avaliação (agora especificado na NBR ISO/IEC 14598);

- coordenação de seu conteúdo com a NBR ISO/IEC 14598-1. (NBR, 2003,p. 2)

Já Figura 1, apresenta um esboço da relação entre as normas 14598-1 e 9126-1. A primeira trata da avaliação de produto de software através das suas subdivisões (partes) 14598-2 (planejamento e gestão), 14598-3 (processo para desenvolvedores), 14598-4 (processo para adquirentes),14598-5 (processo para avaliadores) e 14598-6 (documentação de módulos). A 9126-1 trata das características de qualidade de softwares (funcionalidade, confiabilidade, usabilidade, eficiência, manutenabilidade e portabilidade), em seguida são apresentadas os componentes da norma 9126-2 (trata das métricas externas subcaracterísticas correlacionadas), 9126-3 (métricas internas e suas subcaracterísticas) e 9126-4 (métricas de qualidade em uso):

Mais especificamente sobre a ISO/IEC 9126, o esboço apresenta a relação entre métricas internas (podem ser aplicadas a um produto de software não executável como uma especificação ou código-fonte durante o projeto do sistema) e métricas externas (medidas do comportamento do sistema do qual o software é uma parte, através de teste, operação e observação do software executável ou do sistema), que em conjunto, resultam em componentes do produto de software. Dessa forma, os efeitos do produto do software, dessa forma, seriam a consequência da percepção da qualidade de uso do mesmo (ABNT, 2003). 


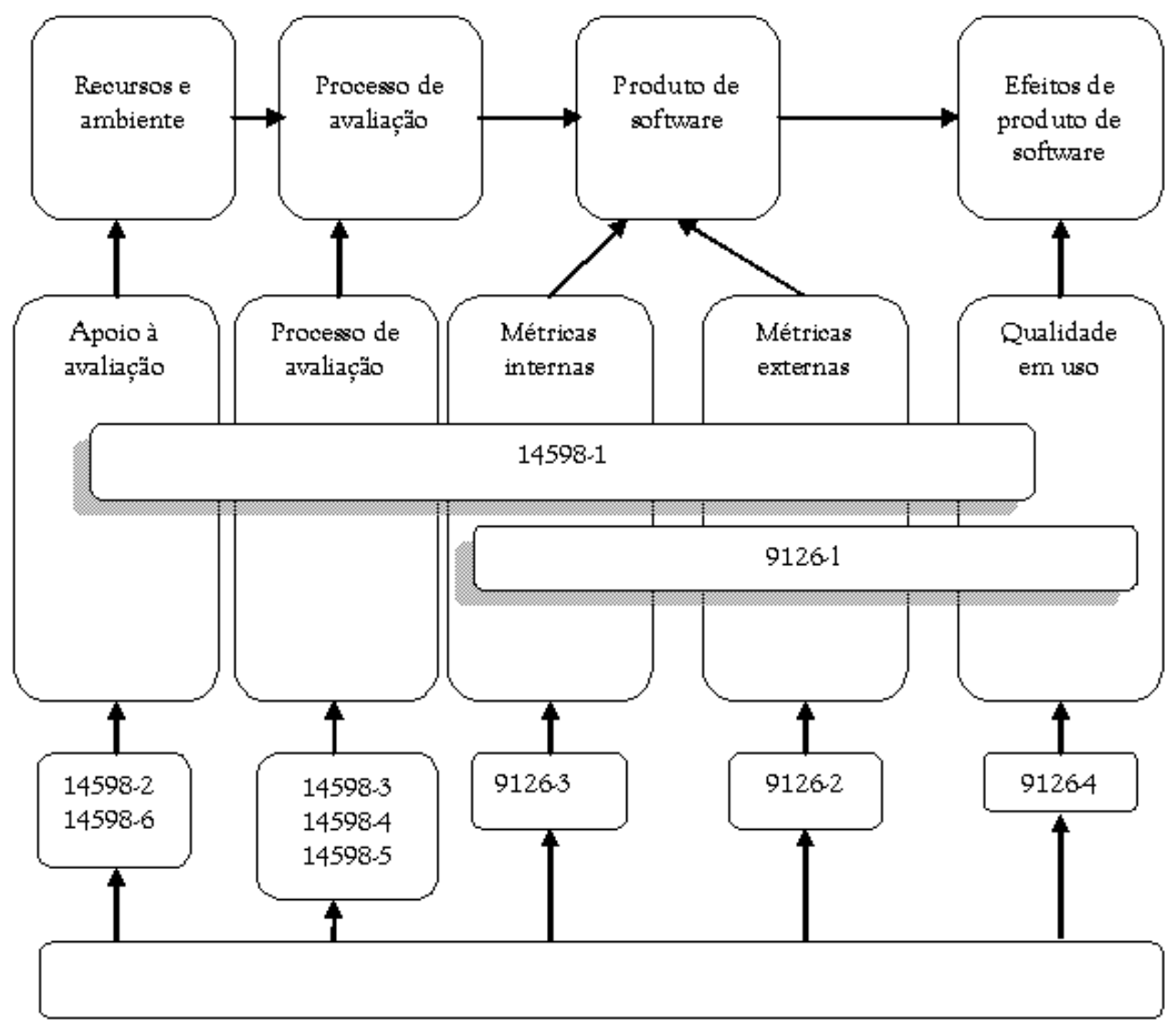

Figura 1. Relação entre normas ISO/IEC 9126 e 14598

Fonte: Adaptado de NBR (2003, p. 2)

A ABNT (2003) define a qualidade em uso de um sistema informatizado como, a capacidade do produto de software de permitir aos usuários específicos atingirem metas relativas às suas operações com eficácia, produtividade, segurança e satisfação em um contexto de uso específico, conforme esboçado na Figura 2:

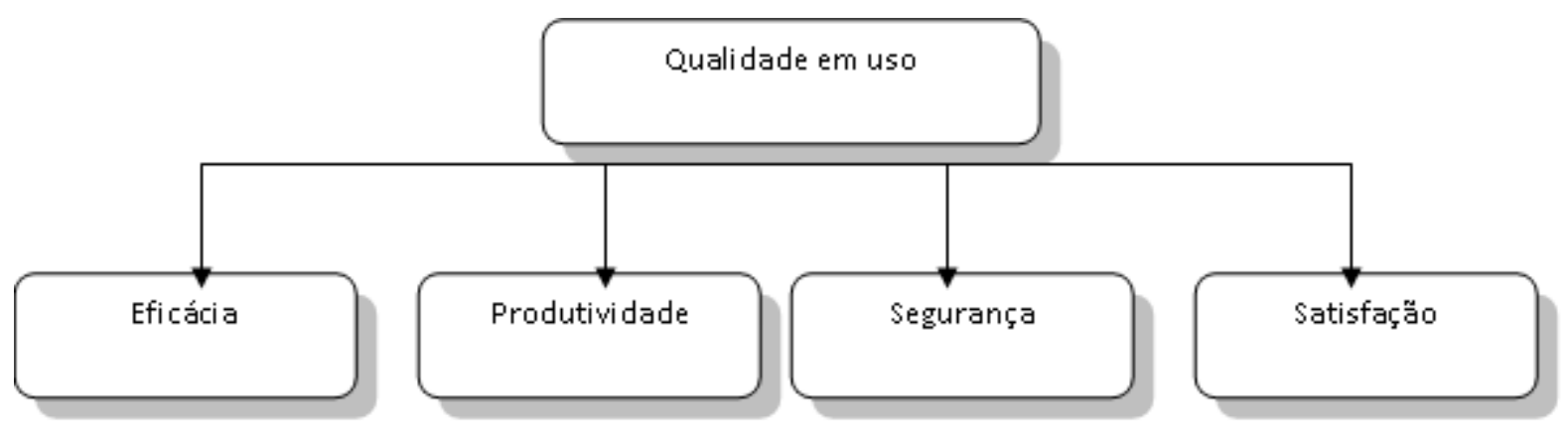

Figura 2. Modelo de qualidade para qualidade de uso

Fonte: Adaptado de ABNT (2003, p.11) 
A norma 9126, conforme ABNT (2003, p. 11), reforça ainda que, qualidade em uso é "a visão da qualidade sob a perspectiva do usuário". Esta, também apresenta as seguintes definições para os quatro quesitos que a compõe:

a) Eficácia: capacidade que o produto de software tem de proporcionar que usuários atinjam metas com acurácia e completitude, em um contexto de uso especificado;

b) Produtividade: é a capacidade do produto de software de permitir que seus usuários empreguem quantidade apropriada de recursos em relação à eficácia obtida, também em um contexto de uso específico;

c) Segurança: potencial do produto de software, em um determinado contexto, de apresentar níveis aceitáveis de riscos de danos a pessoas, negócios, propriedades ou ao ambiente.

d) Satisfação: capacidade do produto de software de satisfazer seus usuários, também levando em consideração o contexto de uso.

Vilas Boas (2007) cita que, a avaliação de produto de software tem sido uma das formas empregadas por organizações que produzem ou adquirem software para obtenção de maior qualidade nesses produtos. $\mathrm{O}$ autor ainda acrescenta que, para que a avaliação seja mais eficiente, é importante que se aplique um modelo de qualidade que permita estabelecer e avaliar requisitos de qualidade (ISO 9126) e também que o processo de avaliação (ISO 14598) seja bem definido e estruturado.

Ainda em relação ao quesito produtividade, Martins e Laugeni (2015), afirmam que, a forma de medir ou avaliar a produtividade das organizações, tem sido motivo de incessantes estudos por pesquisadores de áreas diferentes, não havendo, na opinião dos autores, um consenso geral entre eles. No entanto, segundo eles, os estudiosos são unânimes no que se refere aos benefícios decorrentes do aumento da produtividade a exemplo de: maiores lucros, menores custos e impactos positivos de vida da sociedade.

Já sobre eficácia, os mesmos autores afirmam que é”[...] a medida que quão próximo se chegou dos objetivos previamente estabelecidos. Assim, uma decisão ou ação é tanto quanto mais eficaz quanto mais próximo dos objetivos estabelecidos chegaram aos resultados obtidos”. Enquanto para Drucker (1997) a eficácia concentra-se no sucesso em relação ao alcance de objetivos, centrando-se principalmente para os aspectos externos da organização. 
A perspectiva do quesito satisfação para Johnson, e Fornell (1991) numa visão de gestão pode ser percebida como específica em uma transação e/ou satisfação acumulada. Ainda de acordo com os autores, pesquisadores das diversas áreas da administração concordam no que tange à satisfação como medida individual, ou como avaliação de uma experiência particular com certo produto ou serviço.

\section{Administração Pública.}

Bresser-Pereira (2005), afirmando que, na administração o foco nos resultados, não é só nas perspectivas financeira e orçamentária, mas no acesso e agilidade dos serviços públicos, tomou dimensão significativa para indicadores de avaliação positiva dos projetos de gestão dos governos nas últimas décadas.

O serviço público, a exemplo das instituições privadas, possui procedimentos internos próprios e atividades suscetíveis às mudanças ambientais, que refletem nos esforços organizacionais por atualização direcionada à sua qualidade, seja na esfera da manutenção da máquina pública ou para a regulação dos serviços prestados à sociedade. Porém, diferentemente da iniciativa privada, o serviço público está assentado na lógica e restrições da legislação que regem a administração pública (Kon, 2004).

Kon (2004) ainda defende que, em geral, os serviços públicos tendem a ser analisados não totalmente pelos critérios econômicos relativos a lucros e/ou custos, mas muitas vezes por critérios sociais. Tais peculiaridades os diferem de forma significativa dos serviços advindos da iniciativa privada, entretanto isso não fez com que as ideias de reestruturação do setor público deixem de ser assunto de relevância para os governos. Nesse sentido, a autora enumera alguns fatores que, desde a década de 1960, estimularam muitos países do mundo estudar e aplicar a reestruturação do setor, devido:

a) Demandas crescentes de melhoria e aperfeiçoamento de saúde e educação;

b) Expansão da infraestrutura de comunicação e transportes;

c) Na década de 1980 os altos gastos com defesa pelos países envolvidos na Guerra Fria;

d) Ênfase nos aspectos orçamentários nacionais em relação a previdência (aumento da população de idosos); 
e) Demandas para cuidados (assistência) com crianças e serviços correlacionados, em virtude de mudanças na composição familiar;

f) Medidas intervencionistas (entre 1960 e 1970) em relação ao crescimento econômico e reestruturação, requerendo maior número de trabalhadores governamentais;

g) O crescimento do desemprego e a necessidade de geração de postos de trabalho.

Para Faria (2009), nas décadas de 6o, 70 e 8o, em função de sucessivas crises que abalaram a estrutura de sustentação do Estado de Bem-Estar Social (e suas variantes), no mundo em geral, a Administração Pública vem sendo cada vez mais confrontada com a necessidade de aumentar sua eficiência, diminuir seus custos, enxugar sua estrutura, aumentar sua agilidade e tornar-se mais transparente e democrática, a qual, segundo o mesmo autor, quase sempre, tomaram como base instrumentos de gestão originalmente desenvolvidos para a iniciativa privada.

Esta necessidade de implementação de serviços públicos com mais eficiência aliados às pressões por modelos de gestão voltados para a esfera pública nos dias atuais tem como motivador as necessidades de clientes (sociedade) cada vez mais exigentes de qualidade dos serviços prestados na administração pública (La Falce, et al., 2012). Os autores ainda pontuaram a criação no Brasil de um modelo de excelência na gestão pública com objetivo de melhoria das práticas de gestão nesta esfera, o GESPUBLICA.

\section{Sistemas de Informação.}

Uma vez que este estudo se propõe a tratar da relação entre usuários e sistema de informação, ressalta-se a necessidade de se apresentarem seu conceito e sua aplicabilidade nas organizações. Os sistemas de informação têm sido ferramentas de grande importância para que as empresas possam executar suas tarefas com eficácia, a qual se refere Mattos (2010, p. 195) como a “qualidade de produzir bons resultados". Segundo Batista (2012, p. 38), o termo sistema pode ser definido como "Disposição de partes de um todo, que de maneira coordenada, formam a estrutura organizada, com a finalidade de executar uma ou mais atividades ou, ainda, um conjunto de eventos que se repetem ciclicamente na realização de tarefas predefinidas". 
Stair (1998) cita que sistemas são caracterizados por elementos que interagem para atingir objetivos e os estudos sobre estes sistemas, de acordo com Costa e Ramalho (2010) evoluíram e são usados em diversas áreas da ciência como humanas e sociais, além da área de tecnologia.

Complementarmente, um sistema, de acordo com Do Vale (2013), onde ocorrem processos de interação, soma, mecanização, centralização, competição e finalidade, representando a entrada e saída de dados que são refinados para serem compreendidos como informações no contexto das organizações (Do Vale, 2103).

Segundo Araújo (1995), o sucesso da abordagem sistêmica onde compreende-se as tarefas das organizações que podem ser informatizadas são chamados de sistemas de informação, sendo que estes objetivam permitir comunicação e acesso às informações registradas no sistema.

Atualmente as organizações estão inseridas em ambiente, onde tecnologias são convergentes e isto afeta as tarefas e pessoas (Moresi, 2001). Essa mudança de aplicativos e portabilidade permite que os dados sejam acessados de diversas formas e dispositivos que geram aumento da quantidade de dados disponibilizados e as organizações necessitam de sistemas de informação para gerar uma análise de eficiência e eficácia Davenport, e Kim (2014).

Neste cenário onde a disponibilidade de dados significa que quase toda atividade da empresa moderna pode ser considerada passível de uso em sistemas de informação frente a necessidade de controle e gestão das organizações com melhor emprego dos recursos, sejam estes públicos ou privados justificam investimentos em sistemas governamentais e empresariais.

\section{O SIAFI.}

Sendo de interesse desta pesquisa analisar a aplicação de um sistema de informação, o SIAFI - Sistema Integrado de Administração Financeira no IFNMG campi Januária e Montes Claros é importante ressaltar o que, na perspectiva da informatização de processos, Laudon, e Laudon (2012), discorrem que, os sistemas de informação devem ser percebidos como ferramentas auxiliares para as atividades meio e fim das organizações. Contudo, observa-se 
que o custo cada vez menor dos computadores e a onda de gestão integrada por software têm incentivado, inclusive, o serviço público em investir parte de seus recursos na aquisição dessas ferramentas. Já de acordo com Graeml (2003, p.28):

A tecnologia por si só não vale nada para o negócio. O que importa é como a informação gerada por ela é capaz de proporcionar melhor atendimento às necessidades de seus clientes. São os novos produtos e serviços, ou o valor agregado a eles e aos processos de negócios afetados pela TI, que garantem o retorno do investimento para a empresa. Esses benefícios podem ser bastante intangíveis e, portanto, de difícil mensuração e avaliação. (Graeml, 2003, p.28)

Mais especificamente sobre o SIAFI, de acordo com a Secretaria do Tesouro Nacional (STN) (2011), a criação desta Secretaria, vinculada ao Ministério da Fazenda, através do Decreto n. 92.452, de 10 de março de 1986, que tem, dentre outras atribuições, o objetivo de promover a modernização e a integração dos sistemas de programação financeira, de execução orçamentária e de contabilidade dos órgãos e entidades públicas do Governo Federal, sendo tal decreto, determinante para a implementação do Sistema Integrado de Administração Financeira do Governo Federal naquela época.

Mota (2005, p. 193) reforça o conceito do SIAFI a seguir:

O Sistema integrando de Administração Financeira do Governo Federal - SIAFI é o sistema de teleinformática que processa a execução orçamentária, financeira, patrimonial e contábil dos órgãos e entidades da Administração Federal, com a utilização de técnicas eletrônicas de tratamento de dados, objetivando minimizar custos e proporcionar eficiência e eficácia à gestão dos recursos públicos alocados no Orçamento Geral da União - OGU. (Mota, 2005, p. 193) 
Quanto ao cenário em que consolidava-se o projeto do sistema SIAFI, o STN (2011), afirma que até o exercício de 1986, o Governo Federal enfrentava uma série de problemas de natureza administrativa que impedia a preparação do orçamento unificado, estabelecido para vigorar em 1987. A seguir são listados alguns dos problemas mais relevantes apontados:

a) Os controles de disponibilidades orçamentárias e financeiras eram exercidos a partir de registros manuais;

b) $\mathrm{O}$ uso da contabilidade como simples instrumento de registros formais, pela dificuldade de acesso às modernas técnicas de administração financeira;

c) Em média ocorriam atrasos de, pelo menos, quarenta e cinco dias entre o encerramento do mês e o levantamento das demonstrações orçamentárias, financeiras e patrimoniais, inviabilizando o uso das informações com fins gerenciais;

d) Incompatibilidade e falta de padronização/organização dos dados em decorrência da diversidade de fontes de informações, que comprometiam o processo de tomada de decisões;

e) Inexistência de integração dos sistemas de informações no âmbito federal;

f) Estoques ociosos de moeda espalhados por diversas contas correntes do governo, o que dificultava ainda mais a administração de caixa.

Anastasia e Melo (2002) numa perspectiva de mudança do cenário citado anteriormente, apontam que, nas últimas décadas, os poderes Executivo e Legislativo, no plano federal, têm tomado algumas decisões acertadas quanto a gestão pública, dentre elas, os autores destacam o funcionamento do SIAFI, como principal instrumento de administração orçamentária e financeira da União, por meio do qual são obtidas as informações que subsidiam o balanço geral da União e os relatórios de execução do orçamento e de administração financeira, que compõe, a demonstração das contas apresentadas ao Congresso Nacional pelo Presidente da República.

A seguir serão apresentados os pressupostos metodológicos da pesquisa realizada. 


\section{Metodologia}

Este artigo adotou o critério de classificação de pesquisa proposto por Vergara (2013). Foi adotada a pesquisa descritiva, pois teve como objetivo descrever a percepção de qualidade de serviços do sistema SIAFI em uma organização pública. Vergara (2013) descreve este tipo de pesquisa, como aquela que expõe características de determinada população ou determinado fenômeno. Em relação aos meios de pesquisa, este trabalho caracteriza-se como uma pesquisa de campo, que é segundo Vergara (2013), uma investigação empírica realizada no local onde ocorre um fenômeno.

A abordagem seguida neste trabalho foi de natureza qualitativa. Quanto a técnica de coleta utilizou-se a entrevista semi-estruturada, composta de perguntas baseadas nas quatro dimensões norteadas de qualidade de uso de software, que compõem a ISO/IEC 9126: "satisfação”, “segurança”, “eficácia”, “produtividade” e questões referentes a dados demográficos e profissionais dos participantes. O roteiro de entrevista foi elaborado pelos autores em função das características de cada dimensão da norma ISO/IEC 9126 e relatado no quadro 1.

\begin{tabular}{|c|c|c|}
\hline Dimensão & Características segundo ISO/IEC 9126 & Pergunta \\
\hline Satisfação & $\begin{array}{l}\text { Capacidade do produto de software de } \\
\text { satisfazer seus usuários, dentro do contexto de } \\
\text { uso específico }\end{array}$ & $\begin{array}{l}\text { O SIAFI satisfaz as suas } \\
\text { necessidades r como } \\
\text { usuário do sistema? Por } \\
\text { quê? }\end{array}$ \\
\hline Segurança & $\begin{array}{l}\text { Potencial do produto de software, em um } \\
\text { determinado contexto, de apresentar níveis } \\
\text { aceitáveis de riscos de danos a pessoas, } \\
\text { negócios, propriedades ou ao ambiente. }\end{array}$ & $\begin{array}{l}\text { O SIAFI possui falhas? } \\
\text { Justifique. }\end{array}$ \\
\hline Eficácia & $\begin{array}{l}\text { Capacidade que o produto de software tem de } \\
\text { permitir que usuários atinjam metas } \\
\text { especificadas com acurácia e completitude, em } \\
\text { um contexto de uso especificado }\end{array}$ & $\begin{array}{l}\text { O SIAFI é fácil de ser } \\
\text { usado? Por quê? }\end{array}$ \\
\hline Produtividade & $\begin{array}{l}\text { Capacidade do produto de software de } \\
\text { permitir que seus usuários empreguem } \\
\text { quantidade apropriada de recursos em relação } \\
\text { à eficácia obtida, em um contexto de uso } \\
\text { especificado }\end{array}$ & $\begin{array}{l}\text { O SIAFI é rápido? } \\
\text { Comente. }\end{array}$ \\
\hline
\end{tabular}

Quadro 1. Características das dimensões da ISSO/IEC 9126 e perguntas relacionadas Fonte: Elaborado pelos autores. 
A entrevista foi aplicada a todos os funcionários usuários do Sistema SIAFI, nos campi Januária e Montes Claros, lotados em diferentes segmentos da instituição, tanto aos denominados usuários de nível operacional (relacionados à alimentação rotineira do sistema) quanto aos de nível gerencial que formalmente ocupam cargo de comissão na instituição

A aplicação teve como importância registrar de cada usuário do sistema seu julgamento quanto à qualidade percebida individual (norteada pelas quatro dimensões constantes no instrumento de pesquisa), externalizando assim, sua opinião, bem como a percepção de performance para cada atributo. A duração das entrevistas, realizadas individualmente, tiveram tempo médio de duas horas.

A técnica de análise adotada por esta pesquisa foi a análise de conteúdo, que é definida como:

[...] um conjunto de técnicas de análise das comunicações, utilizando procedimentos sistemáticos e objetivos de descrição do conteúdo da mensagem, e cuja intenção consiste na inferência de conhecimentos relativos às condições de produção (ou, eventualmente, de recepção), inferência esta que recorre a indicadores (quantitativos ou não) (Bardin, 1977, p.38).

Para Franco (2008, p.42) a importância do uso da técnica baseia-se na justificativa de que, dados relativos a uma mensagem, devem estar relacionados necessariamente no mínimo a outro dado. A mesma continua afirmando que "[...] uma informação puramente descritiva não relacionada a outros atributos ou características do emissor é de pequeno valor".

\section{Apresentação e Discussão dos Resultados}

É importante ressaltar que as entrevistas foram realizadas durante os meses de junho e julho de 2011, os participantes foram servidores ativos efetivos do IFNMG dos campi Montes Claros e Januária. Os entrevistados tiveram a opção pelo anonimato, sendo estes 
identificados pela pesquisa através da numeração de 1 a 12. Os enumerados 1,7 e 8 (marcados por * nos quadros a seguir) foram identificados como servidores em cargo de comissão (função gerencial). O aplicador registrou também informações sobre:
a) Tempo de trabalho na instituição;
b) Tempo de trabalho como usuário do SIAFI;
c) Idade do entrevistado;
d) Grau de escolaridade;
e) Área de formação.
f) Se acessa ou não o módulo SIAFI gerencial

\begin{tabular}{|c|c|c|c|c|c|c|}
\hline Usuário & $\begin{array}{l}\text { Tempo no } \\
\text { IFNMG }\end{array}$ & $\begin{array}{l}\text { Tempo como } \\
\text { usuário SIAFI }\end{array}$ & Idade & Escolaridade & Área de formação & $\begin{array}{l}\text { Acessa SIAFI } \\
\text { gerencial? }\end{array}$ \\
\hline $1^{*}$ & 7 anos & 7 anos & 32 anos & $\begin{array}{l}\text { Pós- } \\
\text { graduação }\end{array}$ & Administração & Não \\
\hline 2 & 2 anos & 2 anos & 41 anos & Graduação & Ciências contábeis & Não \\
\hline 3 & 1 ano & 1 ano & 26 anos & $\begin{array}{l}\text { Pós- } \\
\text { graduação }\end{array}$ & Administração & Sim \\
\hline 4 & 2 anos & 2 anos & 47 anos & Graduação & Gestão Comercial & Não \\
\hline 5 & 2 anos & 2 anos & 34 anos & Graduação & Ciências Contábeis & Não \\
\hline 6 & 26 anos & 18 anos & 52 anos & $\begin{array}{l}\text { Pós- } \\
\text { graduação }\end{array}$ & Gestão Pública & Não \\
\hline $7^{*}$ & 16 anos & 3 anos & 40 anos & Graduação & $\begin{array}{l}\text { Análise de } \\
\text { Sistemas }\end{array}$ & Não \\
\hline $8^{*}$ & 7 anos & 7 anos & 27 anos & Ensino Médio & - & Sim \\
\hline 9 & 2 anos & 1 ano & 38 anos & Graduação & Administração & Não \\
\hline 10 & 4 anos & 2 anos & 54 anos & Ensino Médio & - & Não \\
\hline 11 & 1 ano & 1 ano & 37 anos & $\begin{array}{l}\text { Pós- } \\
\text { graduação }\end{array}$ & Administração & Não \\
\hline 12 & 1 ano & 1 ano & 32 anos & $\begin{array}{l}\text { Pós- } \\
\text { graduação }\end{array}$ & Ciências Contábeis & Não \\
\hline
\end{tabular}

Quadro 2. Características dos usuários do SIAFI no IFNMG campi Januária e Montes Claros.

Fonte: Dados da pesquisa 
De maneira sintética, a partir de análise estatística descritiva simples observou-se que a maioria dos usuários do sistema tem formação superior ou pós-graduação (83\%), têm idade média de 38 anos, quase todos trabalham apenas entre 1 e 2 anos na instituição. Observou-se também que, a maioria tem experiência com o sistema que varia entre 1 e 7 anos e apenas dois acessam o módulo gerencial do SIAFI.

Após esta avaliação inicial passou-se a etapa de avaliação das quatro dimensões sobre a qualidade percebida pelos usuários do SIAFI, satisfação, segurança, eficácia e produtividade.

Quanto ao primeiro questionamento, que contemplou sobre "satisfação", pôde-se registrar através do processo de categorização o constante no Quadro 3:

\begin{tabular}{|c|c|}
\hline Usuários & Respostas \\
\hline 1 & $\begin{array}{l}\text { Sim. Porque permite realizar todos os tipos de pagamentos e outros documentos } \\
\text { que necessito. }\end{array}$ \\
\hline 2 & $\begin{array}{l}\text { Não totalmente. Por que existem muitas informações e recursos em sistemas } \\
\text { mais modernos, em outras plataformas que o SIAFI não consegue captar. }\end{array}$ \\
\hline 3 & Sim. Com ele consigo efetuar as operações de que necessito no setor. \\
\hline 4 & Sim. Para a finalidade exigida sim, pois consigo realizar as minhas tarefas \\
\hline 5 & $\begin{array}{l}\text { Sim o Sistema está organizado em módulos nos quais estão contidas diversas } \\
\text { transações, onde são efetivamente executadas as inúmeras operações, desde a } \\
\text { entrada de dados até consultas }\end{array}$ \\
\hline 6 & $\begin{array}{l}\text { Sim. A satisfação se dá pela condição que o sistema oferece para controlar os } \\
\text { recursos orçamentários. }\end{array}$ \\
\hline 7 & $\begin{array}{l}\text { Não. Algumas informações não podem ser consolidadas. Poderia existir filtros } \\
\text { para facilitar. }\end{array}$ \\
\hline 8 & $\begin{array}{l}\text { Não. O SIAFI não possibilita a extração de relatórios, dificultando a elaboração } \\
\text { de planilhas, gráficos e outros documentos necessários ao desempenho das } \\
\text { atividades de cunho gerencial. }\end{array}$ \\
\hline 9 & $\begin{array}{l}\text { Sim. Por que o processo de consulta por vezes é muito multifacetado, } \\
\text { oferecendo funções diversas que não remetem a uma informação sintetizada. }\end{array}$ \\
\hline 10 & $\begin{array}{l}\text { Sim. Minha participação como usuário do SIAFI é limitada. No módulo } \\
\text { específico de atuação (conformidade de gestão), estão satisfeitas as necessidades } \\
\text { para o que o sistema foi concebido, por que visa basicamente ao } \\
\text { acompanhamento da gestão orçamentária e financeira da instituição por etapas. }\end{array}$ \\
\hline 11 & $\begin{array}{l}\text { Sim. O SIAFI possui diversas funções e comandos que facilitam o acesso ao } \\
\text { sistema e às informações. }\end{array}$ \\
\hline 12 & $\begin{array}{l}\text { Sim. Por ter pouco tempo que utilizo o sistema por conhece-lo pouco e algumas } \\
\text { vezes por desconhecimento não consigo e não sei como obtê-la via sistema. Ao } \\
\text { mesmo tempo a operacionalização de alguns módulos é prática e fácil. }\end{array}$ \\
\hline
\end{tabular}

Quadro 3. Respostas dos usuários do SIAFI, se estão satisfeitos com o sistema

Fonte: Dados da pesquisa 
Em linhas gerais, através do exposto, pôde-se entender que os usuários, do SIAFI nos campi pesquisados apresentaram-se satisfeitos basicamente em razão de o sistema oferecer o atributo de auxiliar de maneira perceptível os servidores em executar suas atividades diárias (a satisfação neste caso está ligada à apresentação de resultados instantâneos que o sistema pode executar quando os servidores o utilizam). Quanto à categoria relativa à interface do usuário com o SIAFI (organização do sistema), os entrevistados registraram que o sistema tem a capacidade de conduzi-los a resultados que eles tinham como expectativas a ser alcançadas. Isso pode demonstrar que a satisfação deles está também ligada ao cumprimento do que se espera acerca de recursos básicos de um sistema de administração financeira.

É interessante também destacar que os usuários que se apresentaram insatisfeitos, entrevistados “2","7" e "8" demonstraram tais motivos (divididos em duas categorias básicas) como geradores dessa postura devido à forma como saídas básicas do sistema, utilizadas diariamente (consultas em tela e relatórios impressos) se apresentam incompletas, sem os dados necessários a suprir suas necessidades profissionais, incapacidade do sistema consolidar informações e também em função de obsolescência.

Nos estudos de Winsniewski, e Donelly (1996) foram demonstrados a importância de se satisfazer as necessidades dos clientes internos e externos no âmbito do serviço público. Neste sentido o sistema SIAFI na percepção da maioria tem buscado atender as expectativas do objetivo do sistema com interface com usuários (clientes externos).

Sobre a dimensão "segurança", a partir do questionamento sobre a existência ou não de falhas por parte do SIAFI, organizou-se pela técnica de análise o Quadro 4 a seguir:

\begin{tabular}{|l|l|}
\hline Usuários & Respostas \\
\hline $\mathbf{1}$ & $\begin{array}{l}\text { Sim. Pois ele não critica algumas situações como por exemplo, ao criar uma lista } \\
\text { de credor (LC) ele aceita incluir o credor mais de uma vez na mesma lista e não } \\
\text { critica a situação, mas acredito que em geral o sistema é seguro. }\end{array}$ \\
\hline $\mathbf{2}$ & $\begin{array}{l}\text { Não vejo falhas na segurança do SIAFI, ao contrário, ele é muito seguro. } \\
\text { Sim. Pois operações que devem ser feitas em redundância, tal qual registro de } \\
\text { comandos, após faltar apropriação de NF com contrato e ainda ao incluir conta } \\
\text { corrente é confuso. }\end{array}$ \\
\hline 4 & $\begin{array}{l}\text { Sim. Quanto a segurança o sistema por depender da internet, não salva } \\
\text { informações automaticamente, podendo o usuário, perder todas as informações. } \\
\text { Creio que poderia ter um backup automático. O usuário pode errar em algum } \\
\text { procedimento e dependendo do erro o SIAFI as vezes não recusa de imediato tal }\end{array}$ \\
\hline
\end{tabular}




\begin{tabular}{|c|c|}
\hline & $\begin{array}{l}\text { ação, isso poderia ser melhorado se houvesse maneira de analisar } \\
\text { inconsistências. }\end{array}$ \\
\hline 5 & $\begin{array}{l}\text { Acredito que o SIAFI possui falhas mínimas e que não interferem em relação à } \\
\text { segurança do mesmo. }\end{array}$ \\
\hline 6 & $\begin{array}{l}\text { O SIAFI é um sistema em constante evolução, na tentativa de sempre melhorar } \\
\text { seu desempenho, corrigindo falhas e implementando novas tecnologias. O } \\
\text { sistema é seguro, e confiável pois é preciso ser cadastrado formalmente, ter } \\
\text { senha e perfil de abrangência conforme legislação vigente. }\end{array}$ \\
\hline 7 & Não tenho conhecimento. \\
\hline 8 & $\begin{array}{l}\text { Não identifiquei nenhuma falha, já que ele traduz fielmente as informações nele } \\
\text { inseridas, além de impossibilitar o acesso dos dados por pessoas estranhas. }\end{array}$ \\
\hline 9 & $\begin{array}{l}\text { Sim. Em relação a falta de alinhamento de parâmetros com outros sistemas } \\
\text { como o SIASG com o qual o SIAFI faz conexão. A falha consiste na aceitação pelo } \\
\text { SIAFI, no caso de licitações, de valores de itens com até quatro casas decimais, } \\
\text { porém quando vai adjudicar o processo todo ele é prejudicado porque os itens } \\
\text { têm mais de duas casas decimais, sem efeito. }\end{array}$ \\
\hline 10 & $\begin{array}{l}\text { O SIAFI é um sistema dinâmico e complexo que não é isento de falhas. A falha } \\
\text { propriamente dita não é percebida, está no processamento interno do programa, } \\
\text { mesmo que o usuário insira dados corretos. }\end{array}$ \\
\hline 11 & $\begin{array}{l}\text { Aparentemente o SIAFI não possui falhas. Apesar do meu pouco tempo como } \\
\text { usuário, não percebi falhas no sistema, ao contrário, para ser acessado, ele exige } \\
\text { duas senhas SERPRO e SIAFI que são mudadas de tempo em tempo de forma a } \\
\text { inibir acesso indevido. }\end{array}$ \\
\hline 12 & Não. Pelo tempo que utilizo o sistema ainda não detectei falhas nele. \\
\hline
\end{tabular}

Quadro 4. Respostas dos usuários do SIAFI sobre segurança do software

Fonte: Dados da pesquisa

Na percepção dos usuários do SIAFI dos campi de Januária e Montes Claros, o sistema pode ser considerado como um sistema seguro na visão dos entrevistados “", "3","4",6","8","9" “11" e “12", por estar em constante aperfeiçoamento (em evolução - em constante reavaliação) e principalmente por ter a capacidade de impedir o acesso indevido por não-usuários. Este último item foi o mais apontado, expressando o que para estes, reflete o "esforço do sistema" em exigir cadastramento completo de seus usuários, além de mais de uma senha de acesso. Os relatos abaixo ilustram os resultados:

Já os usuários que entendiam o SIAFI como falho, em termos de segurança, pelos entrevistados “2","5"e “10", destacaram vários pontos que foram categorizados na pesquisa como quesitos relacionados à entrada, processamento e guarda (backups) dos dados.

É importante também ressaltar que o termo segurança para aqueles que não detectaram falhas do sistema nesse quesito, limitou-se basicamente às barreiras de acesso 
aos dados e informações, promovidas por senhas de acesso, apesar de a norma NBR 9126-1 apresentar o termo com definição mais ampla.

Um destaque das respostas dos entrevistados ficou por conta do entrevistado " 7 " que afirmou não ter conhecimento sobre o assunto e aparentemente pouca preocupação sobre o tema.

Kon (2013) afirma que os serviços devem ser tratados como atividade estratégica da organização, e a percepção de segurança tem impacto na avaliação dos serviços da organização. Pensamento este alinhado com percepções de confiabilidade de outros estudos da literatura tais como os de Fadel, e Regis Filho, 2009; Raja, e Kumar, 2011 e La Falce et al. (2012).

A terceira dimensão abordada na pesquisa foi "eficácia”, também apontado pela norma. No Quadro 5, apresentam-se as respostas:

\begin{tabular}{|c|c|}
\hline Usuários & Respostas \\
\hline 1 & Não, pois possui muitos comandos, eventos e códigos. É bastante complexo. \\
\hline 2 & Sim, as informações estão bem divididas. \\
\hline 3 & $\begin{array}{l}\text { Sim, por que os comandos são padronizados e aprendendo um comando, por } \\
\text { analogia, consegue-se deduzir outros. }\end{array}$ \\
\hline 4 & $\begin{array}{l}\text { Não, o SIAFI é um sistema muito complexo. Apesar de ser um sistema } \\
\text { padronizado, fica mais fácil sua utilização se o usuário memorizar os } \\
\text { procedimentos ou anota-los. }\end{array}$ \\
\hline 5 & $\begin{array}{l}\text { Não. Pois o sistema tem várias transações e se faz necessário treinamento para } \\
\text { seus usuários para sua operacionalização e recorrer a leitura das macrofunções } \\
\text { do sistema. }\end{array}$ \\
\hline 6 & $\begin{array}{l}\text { Não. Inicialmente deve-se capacitar o usuário, treinamento e atualização } \\
\text { contábil devem ser realizados sempre. }\end{array}$ \\
\hline 7 & $\begin{array}{l}\text { Não. Por ser desenvolvido em uma linguagem antiga, as telas são complicadas. } \\
\text { Difícil por não possuir atalhos. }\end{array}$ \\
\hline 8 & $\begin{array}{l}\text { Não. O sistema requer conhecimentos prévios sobre sua utilização, não é auto- } \\
\text { explicativo, apresenta mensagens de erro de difícil compreensão, aceita inserção } \\
\text { de dados mesmo sendo incorretos, etc. }\end{array}$ \\
\hline 9 & $\begin{array}{l}\text { Não, é moderado. Alguns módulos não são auto-explicativos, exigindo muitas } \\
\text { vezes o auxílio do setor contábil da Secretaria de Educação Tecnológica - SETEC } \\
\text { do MEC. }\end{array}$ \\
\hline 10 & $\begin{array}{l}\text { Apesar de ser dinâmico e complexo, o SIAFI é um sistema muito fácil de ser } \\
\text { utilizado. Os questionamentos ao usuário são apresentados de forma direta e } \\
\text { clara. }\end{array}$ \\
\hline 11 & $\begin{array}{l}\text { Não. O SIAFI possui uma infinidade de comandos que teoricamente facilitariam } \\
\text { o uso, entretanto, nem sempre temos conhecimento dos comandos e não existe } \\
\text { uma "AJUDA" on line que interpretam os comandos e sua utilização de forma } \\
\text { detalhada. }\end{array}$ \\
\hline
\end{tabular}


12

Não. Às vezes, o sistema oferece alguns módulos de fácil utilização, porém talvez por falta de conhecimento do sistema acho ele falho com relação a parte de relatório.

Quadro 5. Distribuição dos motivos apresentados pelos usuários do SIAFI sobre o quesito eficácia do software

Fonte: Dados da pesquisa (2011)

De maneira geral, para os usuários do sistema, o SIAFI pode ser considerado eficaz porque é padronizado. A padronização na opinião deles pode ser vista como uma forma de economizar esforços, trabalhando sempre da mesma maneira, proporcionando a criação de rotinas. Esta padronização é apontada como necessária para a eficácia e facilidade de manuseio por Davenport e Kim (2014). Tal interpretação é reforçada pela expressão apresentadas abaixo:

- “[...] aprendendo um comando, por analogia, consegue-se deduzir outros.”.

Os usuários que divergiram com a primeira opinião e entenderam o SIAFI como difícil afirmam que o sistema gera impedimentos para alcançar resultados almejados, alegam como deficiências principais: a complexidade do sistema e a dificuldade de interpretação de uso de suas ferramentas. Destaca-se, nesse sentido, como exemplificação, a seguinte expressão de um entrevistado:

- “[...] o usuário têm que, decorar ou anotar os procedimentos [...]”;

Outras dificuldades também foram apresentadas a partir de uma possível falta de treinamento prévio dos servidores para o uso do software. Para os entrevistados e usuários do SIAFI “1”, “4”, “5”, “6”, “7”, “8”, “9”, “11” e “12”, existem problemas significativos em relação à apresentação do sistema (interface), para eles as telas são complicadas e as mensagens de erro são de difícil interpretação, muitos comandos, além de não existir, segundo eles, um suporte de sistema on-line. 
No último questionamento, a dimensão "produtividade", também constante na NBR 9126-1, foi abordada através de questionamento a respeito da rapidez de processamento do SIAFI, do qual resultaram as seguintes categorias, dispostas no Quadro 6:

\begin{tabular}{|l|l|}
\hline Usuários & Respostas \\
\hline $1^{*}$ & $\begin{array}{l}\text { Atualmente sim. Mas irá mudar para estrutura web e a tendência é ficar mais } \\
\text { lento. }\end{array}$ \\
\hline 2 & Sim. Exceto quando há muita demanda, mas no geral é rápido. \\
\hline 3 & Sim. Com raras exceções. \\
\hline 4 & $\begin{array}{l}\text { Sim. Normalmente, os procedimentos diários são processados imediatamente } \\
\text { que são transmitidos e os dados são analisados. No dia seguinte o sistema dá um } \\
\text { retorno e acusa alguma correção necessária. }\end{array}$ \\
\hline 5 & $\begin{array}{l}\text { Sim. Pois mesmo interligado em todo o território nacional para atender os } \\
\text { diversos órgãos, tenho poucos problemas com o desempenho e rapidez do } \\
\text { sistema. }\end{array}$ \\
\hline 6 & $\begin{array}{l}\text { Sim. Apenas em alguns períodos específicos pode ficar mais lento. } \\
\text { usuários logados ao mesmo tempo, o tempo de resposta é curto. }\end{array}$ \\
\hline $7^{*}$ & $\begin{array}{l}\text { Sim. Em linhas gerais é rápido, exceto quando está sendo acessado por um de } \\
\text { número muito grande de usuários, ao mesmo tempo, se torna lento, forçando a } \\
\text { reinicialização do sistema. }\end{array}$ \\
\hline 9 & $\begin{array}{l}\text { Sim. O SIAFI é rápido, pois, ao executar determinados comandos, o mesmo } \\
\text { processa rápido os dados e faz um retorno (feedback) também rápido. Ele } \\
\text { propicia que os usuários atinjam seus objetivos com eficiência com adoção de } \\
\text { métodos corretos e ações certas e pontuais. }\end{array}$ \\
\hline 10 & $\begin{array}{l}\text { Sim. O SIAFI é super rápido. O seu desempenho possibilita ao usuário os níveis } \\
\text { requeridos. } \\
\text { Sim. O acesso ao sistema é muito rápido. Não deixa a desejar na rapidez e } \\
\text { desempenho esperado pelos usuários. } \\
\text { Sim. Por ser um sistema que depende de internet para funcionar, a rapidez irá } \\
\text { tenha recursos tecnológicos adequados. }\end{array}$ \\
\hline Rester da velocidade da internet, portanto o sistema é eficiente, desde que \\
\hline 12
\end{tabular}

Quadro 6. Respostas dos usuários do SIAFI a cerca do quesito produtividade Fonte: Dados da Pesquisa

A dimensão produtividade foi o único constante na norma NBR 9126-1 e presente na pesquisa, em que todos entrevistados concordaram como sendo o SIAFI um sistema ágil e rápido.

Através da categorização (proposta pela técnica de análise do conteúdo), pôde-se observar que as expressões usadas pelos usuários direcionavam para a robustez do software. Justificaram também que, apesar de o sistema ser acessado por milhares de usuários ao 
mesmo tempo em todo o país, ainda assim ele continua rápido, atendendo, assim, as expectativas dos usuários em termos de rapidez e desempenho.

Comparadas as expressões dos servidores em cargos de comissão, aos demais que executam atividades operacionais, observou-se que, de maneira inversa (a maioria dos servidores operacionais expressou-se satisfeita), apenas um servidor de tal nível demonstrou-se insatisfeito (usuário 2, quadro 1), apontando, assim, a obsolescência do sistema como fator principal.

Já em relação à segurança do sistema, a maioria servidores de nível gerencial o entende como seguro (dois servidores de três entrevistados), enquanto, que, dos nove servidores operacionais, apenas três (33\%) vêem o SIAFI como um sistema sem falhas.

É interessante observar que, a exemplo dos servidores citados anteriormente, aqueles servidores de nível operacional, em sua maioria, também entendem o sistema como de difícil manuseio, apontando os mesmos motivos dos primeiros. Também na perspectiva da produtividade, independente do nível hierárquico ocupado pelos servidores, estes percebem o sistema como ágil de maneira geral.

Por fim, outro destaque que chama a atenção nesta pesquisa foi a divergência de opinião dos entrevistados com nível gerencial nas dimensões satisfação e segurança, o entrevistado 1, que além de gestor opera o sistema, mostrou mais alinhamento com a visão do nível operacional. Em pesquisas anteriores Milan e Trez (2005), Raja e Kumar, 2011 e La Falce e De Muylder (2013), também identificaram diferenças nas visões de gestores e operadores, o que pode indicar que quando gestores possuem conhecimento da tarefa e do processo, a percepção tende a convergir.

\section{Considerações Finais}

Especificamente acerca das dimensões de qualidade de uso, notou-se na pesquisa que, a interpretação do que venha ser satisfação para a maioria dos usuários do IFNMG é o nível de aplicação prática do sistema, ou melhor, a forma com que o programa facilita as atividades diárias deles. Nesse sentido, a maioria se manifestou satisfeita. Dessa forma Johnson e Fornell (1991), reforçam que existem interpretações diferentes derivadas da análise de satisfação. Segundo os autores, enquanto estudiosos das áreas de Ciências Sociais 
Aplicadas têm preferência pela aferição da satisfação das pessoas como uma representação da qualidade, os psicólogos têm se importado com as expectativas e percepção dos indivíduos como antecedentes da satisfação.

Sobre a segurança, os usuários, de maneira geral, preocuparam-se em apontar problemas relativos à falta de barreiras (testes de inconsistências) na entrada de dados incorretos ou fora de padrão no sistema, o que consequentemente provocaria transtornos nas atividades desses servidores. Uma consequência possível desse problema poderia ser a incógnita do servidor em saber se os possíveis erros apresentados em consultas e relatórios foram originados na entrada dos dados ou no processamento interno do software.

Ressalta-se também que, conforme as entrevistas (ainda em relação à percepção de segurança no sistema) a falta de testes de consistências na alimentação do sistema, provoca retrabalho de alguns usuários, o que consequentemente atingiria outro quesito de qualidade abordado, a produtividade, apesar de todos os entrevistados em suas respostas específicas, entenderem o sistema como ágil, rápido.

É possível, portanto, entender uma correlação estreita entre esses dois quesitos de qualidade de uso de software (segurança e produtividade) de maneira também a sugerir futuros novos estudos sobre eles.

Outro ponto observado de maneira mais geral sobre as entrevistas é que se citou em vários momentos, por usuários diferentes, que o manuseio o sistema é de difícil entendimento. Infere-se, portanto, que, como visto pela própria concepção (criação e desenvolvimento do sistema) do SIAFI, talvez esta conotação (complexo) se deva a exigida abrangência do sistema para diferentes instituições do Governo, devendo ser ele muito mais genérico e menos específico.

Quanto à perspectiva dos servidores com mais tempo de serviço no IFNMG (entrevistados 1, 2, 7 e 8) que, neste caso, por sua vez também são os usuários que há mais tempo utilizam o SIAFI, observou-se que não foram registradas diferenças atenuantes em relação às respostas dos demais servidores com menos tempo de trabalho na instituição ou com menor tempo de uso do software. Mas vale ressaltar que, mesmo com maior tempo destes na instituição e como usuários, a dificuldade em manusear o SIAFI continuou sendo um problema comum apontado pela maioria deles. 
Observou-se ainda que, dos três usuários entrevistados com cargo em comissão de nível gerencial, apenas um tem acesso ao módulo do software denominado de SIAFI gerencial (módulo destinado a fornecer informações consolidadas para gerentes). Mesmo assim, esse usuário entende que o SIAFI, de maneira geral, não o satisfaz pela deficiência que o sistema tem em apresentar consultas e relatórios necessários ao desempenho de atividades de cunho gerencial. Isto indica, que o conhecimento do sistema, por parte do gestor, que também opera o SIAFI, têm maior alinhamento com os demais usuários. Já descrito na literatura o conhecimento de processo por parte da gestão é fundamental e influência na percepção do usuário.

Por se tratar de um estudo de caso, em que as conclusões obtidas por esta pesquisa não devem ser generalizadas, sugere-se novos estudos acadêmicos que envolvam sistemas de informação utilizados nos serviços públicos, percepção de qualidade pelos usuários podendo inclusive limitar e aprofundar em inferências acerca da produtividade de seus usuários.

Sugere-se, ainda, uma ênfase maior dos responsáveis pela gestão de sistemas no Instituto em investir mais no treinamento de seus usuários, podendo promover, assim, maior confiança deles em relação que executam e, como consequência, também o possível aumento da produtividade desses servidores através a otimização de uso do SIAFI. 


\section{Referências}

Abdi, A., Lind, H., \& Birgisson, B. (2014). Designing appropriate contracts for achieving efficient winter road and railway maintenance with high performance quality. International Journal of Quality and Service Sciences, 6(4), 399 - 415.

Ammenwerth, E., Iller, C., \& Mahler, C. (2006). IT-adoption and the interaction of task, technology and individuals: a fit framework and case of study. BMC medical informatics and decision making, 6(3).

Anastasia, F., \& Melo, C. F. de. (2002). Accountability: Representação e Estabilidade Política no Brasil, In F. Abrúcio, \& R. Loureiro (Orgs.), O Estado numa Era de Reformas: Os Anos FHC. Brasília, MP/Seges, 25-74.

Araújo, V. M. R. H. (1995). Sistemas de informação: nova abordagem teórico-conceitual. Ciência da Informação, Brasília, 24(1).

Associação Brasileira de Normas e Técnicas -ABNT.(2003). NBR ISO/ 9126-1 Engenharia de software - Qualidade de produto Parte 1: Modelo de qualidade. Rio de Janeiro: ABNT.

Bardin, L. (1977). Análise de conteúdo. Lisboa: Edições 70.

Batista, E. (2012). Sistemas de informação: o uso consciente da tecnologia para o gerenciamento. 2 ed. São Paulo: Saraiva.

Bresser-Pereira, L. (2005). Reforma do estado e administração pública gerencial. 4 ed. Rio de Janeiro: FGV.

Chahin, A., Cunha, M., Kinight, P., \& Pinto, S. (2004). A próxima revolução brasileira: eficiência, qualidade e democracia: o governo eletrônico no Brasil e no Mundo. São Paulo: Pearson Prentice Hall.

Costa, L. F. D., \& Ramalho, F. A. (2010). A usabilidade nos estudos de uso da informação: em cena usuários e sistemas interativos de informação. Perspectivas em ciência da informação, Belo Horizonte, 15(1), p. 92-117, jan./abr. 
Davenport, T., \& Kim, J. (2014). Dados demais! Como desenvolver habilidades analíticas para resolver problemas complexos, reduzir riscos e decidir melhor. Rio de Janeiro: Elsevier. (Tradução de Afonso Celso da Cunha.)

Do Vale, C. C. (2013). Teoria geral do sistema: histórico e correlações com a geografia e com o estudo da paisagem. Entre-Lugar, Dourados, 3(6), p. 85-108, jul./dez. 2013.

Drucker, P. (1977). A nova era da administração. São Paulo: Pioneira Thompson.

Fadel, M., \& Regis Filho, G. (2009). Percepção da qualidade em serviços públicos de saúde: um estudo de caso. Revista de Administração Pública, Rio de Janeiro, 43(1), p. o7-22, jan./fev. 2009 .

Faria, L. (2009, setembro). Nova Administração Pública: o processo de inovação na Administração Pública Federal Brasileira visto pela experiência do concurso inovação na gestão Pública Federal. In Anais do Encontro da Associação Nacional de Pós-Graduação e Pesquisa em Administração, São Paulo, SP, Brasil.

Fortes, J. (2012). Contabilidade Pública. 10 ed. Brasília: Franco \& Fortes.

Franco, M. (2008). Análise do Conteúdo. 3 ed. Brasília: Líber livro.

Gil, A. (1999). Sistemas de informações: contábil, financeiros. 3 ed. São Paulo: Atlas.

Graeml, A. (2003). O Alinhamento da Estratégia de TI com a Estratégia Corporativa. 2 ed. São Paulo : Editora Atlas.

Grönroos, C. (2009). Marketing : gerenciamento e serviços. 3 ed. Rio de Janeiro: Campus.

Howells, J., \& Tether, B. (2004). Innovation in Services: Issues at Stake and Trends. Final Report, Commission of the European Communities, Brussels-Luxembourg.

Johnson, M., \& Fornell, C. (1991). A framework for comparing customer satisfaction across individuals and product categories. Journal of Economic Psychology, 12(2) 267-86.

Kon, A. (2004). Economia de serviços: teoria e evolução no Brasil. São Paulo: Elsevier. 
Kon, A. (2013). Atividades de serviços como indutoras do desenvolvimento. Revista da Sociedade Brasileira de Economia Política, 34 (57).

Kotler, P. (2012). Administração de marketing: a edição do novo milênio. 14 ed. São Paulo: Prentice Hall. (Trad. Bazan Tecnologia e Linguística.)

La Falce, J., \& De Muylder, C. (2013) Inovação, qualidade em serviços e empreendedorismo: analise de uma empresa franqueada do setor de varejo no ramo da moda. Gestão e Planejamento, 14(3).

La Falce, J. De Muylder, C., Pressot, I., \& Toivanen; M. L. (2012). Qualidade no serviço Público: Um estudo de caso em uma fundação pública em Minas Gerais. Amazônia, Organizações e Sustentabilidade, 3(2).

Laudon, K., \& Laudon, J. (2012). Sistemas de informações gerencias. 9 ed. São Paulo: Pearson Prentive Hall.

Martins, P., \& Laugeni, F. P. (2015). Administração da produção. 3 ed. São Paulo: Saraiva.

Mattos, A. (2010). Sistemas de informação: uma visão executiva. 2 ed. São Paulo: Saraiva.

Melo, E. (2002). A Lei de Responsabilidade Fiscal e a gestão financeira municipal: um estudo sobre impactos nos mecanismos de controle financeiro da administração municipal de Salvador. Dissertação. Salvador: UNIFACS.

Milan, G., \& Trez, G. (2005). Pesquisa de satisfação: um modelo para planos de saúde, RAEeletrônica, 4(2), jul./dez.

Moresi, E. A. D. (2001). Delineando o valor do sistema de informação de uma organização. Ciência da Informação, Brasília, 29(1) p. 14-24, maio/ago.

Parasuraman, A., Zeithaml, V., \& Berry. L. (1985). A conceptual model for service quality and its implications for future research. Journal al marketing, 49, 41-50.

Paulk, M. (1994) A comparison of ISOgoo1 and the Capability Maturity Model for Software. Technical Report. 
Pencarelli, T., Splendiani, S., \& Cini, (2013). Quality and value in university services, International Journal of Quality and Service Sciences,5(2), 140 - 154.

Pêssoa, M. (2005). Modelo Integrado de Maturidade da Capacidade de Processo. Lavras: UFLA/FAEPE.

Pressman, R. (2011). Engenharia de Software. 7 ed. São Paulo: Makron Books.

Raja, M., \& Kumar, A. (2011) Service Quality: A measure tool for improving quality in education. New York: Lambert Academic Publisher. 216 p.

Rezende, D. (2013). Sistemas de informações organizacionais: guia prático para projetos em cursos de administração, contabilidade e informática. 5 ed. São Paulo: Atlas.

Vergara, S. C. (2013). Projetos e relatórios de pesquisa em administração. 14 ed. São Paulo: Atlas.

Villas Boas, A. (2007). Qualidade e avaliação de produto de software. Lavras: UFLA/FAEPE.

Wisniewski, M., \& Donnelly, M. (1996). Measuring service quality in the public sector: the potential for SERVQUAL. Total Quality Management. 7(4), 357-365.

Submissão: 20/11/2015

Segunda versão: $21 / 08 / 2016$

Terceira versão: $25 / 08 / 2016$

Aceite: 29/o8/2016 